\title{
Hydrodynamic performance of coaxial contra-rotating propeller (CCRP) for large ships
}

\author{
Hassan Ghassemi, Assoc. Prof. \\ Amirkabir University of Technology
}

\begin{abstract}

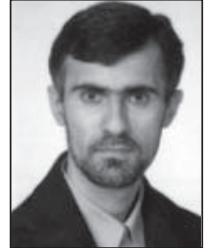

This paper describes a coaxial contra-rotating propeller (CCRP) system to calculate the hydrodynamic characteristics and then obtain the optimum operational condition to install on two different large bulk carrier and VLCC. The method is based on boundary element method (BEM) to obtain the hydrodynamic performance of any complicated configuration such as CRP system, and then the optimum propeller data is obtained by the systematical method at the design condition. We prepared a software package code, namely SPD (Ship Propeller Design), which has model mesh generation, solver and numerical output results. The comparison of the propulsive performance was made between the propeller alone and CRP arrangement. Major finding include good agreement between predictions using the numerical code and experimental data for both ships.
\end{abstract}

Keywords: boundary element method, contra-rotating propeller, CRP, optimum efficiency

\section{INTRODUCTION}

The main aims of the marine propulsor designers are to increase thrust, diminish torque, improve efficiency and to save energy. Most conventional propulsors are working behind the ship hull where the flow is non-uniform, unsteady and also limitation of the propeller diameter due to ship stern. Single propeller produces cavitation at the heavy load condition, but CCRP may provide moderate load on each blade and prevent cavitation. Another case is that the single propeller generates torque, while CCRP cancel the torque and improve the efficiency $[1,2]$.

The history of CRP goes back when a patent was applied by Ericsson (the inventor in 1836) to 45 feet ship. In 1909 and 1939, Italian Navy and US Navy had experimented CRP on a 46 feet and 70 feet steam ship, respectively. Rutundi [3] made a comparison test between CRP and conventional propeller for a 3500 tons naval training ship and has reported an 18\% improvement in the propulsive performance.

Since then, CRP has well been used for torpedoes, small vessels, and of course for aircraft, but there is a difficulty in producing a reliable $\mathrm{CR}$ shafting which can support the large power for application to large merchant ships. In 1988, MHI (Japan) has succeeded in retrofitting 4200 GT with a CRP [4], and in the same year, IHI (Japan) has completed the shop test of Juno's CRP system at the outset. Having been equipped with this CRP system, Juno dealt with the official trial in witch she has achieved a $15 \%$ power saving. After that, some other experimental research have been done at NMRC (in Japan) (before name was SRI) by Ukon, [5, 6, 11, 13, 14].
From the numerical approach during two decades, some work has been done to obtain a better understanding of the system in order to predict its effect on hydrodynamic performance. Yang C-J [1] and Islam et al. [8] was used lifting surface theory and vortex lattice method to calculate the blade loading.

Recently, more attention is being drawn to the development of the contra-rotating podded propulsor (CRPP) system for ship propulsion because of its attractively high energy saving rate as well as lower cavitation and better hydrodynamic performance.

In the current arrangement, a CRPP is placed at the forward end of a pod which is aligned with the local inflow. The powering and cavitation experiments show the performance prediction agree well with measurement.

Nishiyama and Sakamoto [10] designed a CRP system at IHI and on bulk carrier and VLCC.

This paper deals with the following subjects:

* numerical Method of BEM

* mesh Generation

* design concept of CRP on Behind of Ship

* design concept of CRPP

application of the CRP system on the Ship

systematic design

This paper is firstly calculated the hydrodynamic performance of the CCRP using BEM. The calculated results are predicted well with experimental measurements. Systematic design is finally employed to the two ships types (Bulk carrier and VLCC) to obtain the design points. 


\section{DESIGN CONCEPT OF CRP}

\section{Procedure of CCRP designing}

With the principal particulars of the hull and the main engine given, a CRP can be designed as for any single propeller, namely, through reiteration of the following two steps:

(1) Propeller Design in uniform flow: try to find for an optimum design that satisfy the given engine power and revolution speed; then

(2) Modification by considering the non-uniform flow: the propeller designed thus is further modified, so as to better adapt to the non-uniform flow over what has already been considered macroscopically in step (1), in such terms as propeller cavitation, propeller-induced vibration, and strength of blade for the propeller performance in non-uniform flows.

\section{Designing CCRP in uniform flow}

There are two approaches in the design of CRP: one based on lifting surface theory [9], and other utilizing the design diagram based on open water tests on systematic CRP model series [5]. More precise results could be expected from the systematic series data than from the theoretical approach. However, a review of past reports for CRP, the method based on series test data can be found.

Fig. 1 depicts the design procedure and algorithm. Here, the relation between ship speed and resistance $\left(R_{T}-V_{S}\right)$ for the hull, self propulsion test or some empirical formulae $\left(\mathrm{t}, \mathrm{w}, \eta_{\mathrm{R}}\right)$, the number of blade $(Z)$ and axial distance between two propellers $\left(\mathrm{x}_{\mathrm{A}}\right)$ are given. According to systematical method and flowchart, first estimate the revolution number of propeller and its diameter. Then using numerical SPD code, the hydrodynamic characteristics (open water) of propeller alone and CRP system are calculated.

How to calculate the optimum efficiency from the open water diagram? This is the systematic method to obtain the optimum design of the propeller for the ship. From the resistance and the self propulsion test or some empirical formulae, the following relation may be expressed:

$\star$ For single conventional propeller:

$$
\begin{gathered}
\mathrm{K}_{\mathrm{T}}=\frac{\mathrm{T}}{\rho \mathrm{n}^{2} \mathrm{D}^{4}}=\frac{\mathrm{T}}{\rho \mathrm{D}^{2} \mathrm{~V}_{\mathrm{A}}^{2}} \cdot \mathrm{J}^{2}= \\
=\frac{\mathrm{R}_{\mathrm{T}}}{(1-\mathrm{t}) \rho \mathrm{D}^{2}\left[\mathrm{~V}_{\mathrm{S}}(1-\overline{\mathrm{w}})\right]^{2}} \cdot \mathrm{J}^{2}=\mathrm{A} \cdot \mathrm{J}^{2}
\end{gathered}
$$

$\star$ For CRP system:

$$
\begin{gathered}
\mathrm{K}_{\mathrm{T}}=\frac{\mathrm{T}_{\mathrm{F}}+\mathrm{T}_{\mathrm{A}}}{\rho \mathrm{n}_{\mathrm{F}}^{2} \mathrm{D}_{\mathrm{F}}^{4}}= \\
=\frac{\mathrm{R}_{\mathrm{T}}}{(1-\mathrm{t}) \rho \mathrm{D}_{\mathrm{F}}^{2}\left[\mathrm{~V}_{\mathrm{S}}(1-\overline{\mathrm{w}})\right]^{2}} \cdot \mathrm{J}^{2}=\mathrm{B} \cdot \mathrm{J}^{2}
\end{gathered}
$$

This $\mathrm{K}_{\mathrm{T}}$ is quadratic function of $\mathrm{J}$ and intersects with open water curves of $\mathrm{K}_{\mathrm{T}}-\mathrm{J}$ and the optimum solution is obtained from the intersection point, so all the coefficients are obtained from this point $\left(\mathrm{K}_{\mathrm{T}}, \mathrm{K}_{\mathrm{Q}}, \eta_{\mathrm{O}}, \mathrm{J}\right)$. Then, the thrust and torque are obtained from the following:

$$
\begin{gathered}
\mathrm{T}=\mathrm{K}_{\mathrm{t}}\left(\mathrm{J}_{\mathrm{n}, \mathrm{D}}\right) \rho n^{2} \mathrm{D}^{4} ; \mathrm{T}_{\text {Calculated( }(\mathrm{i}+1)} \geq \mathrm{T}_{\text {Required(i) }} \\
\mathrm{Q}=\mathrm{K}_{\mathrm{Q}}\left(\mathrm{J}_{\mathrm{n}, \mathrm{D}}\right) \rho n^{2} \mathrm{D}^{5} ; \mathrm{Q}_{\mathrm{i}+1} \leq \mathrm{Q}_{\mathrm{i}}
\end{gathered}
$$

$$
\begin{gathered}
\mathrm{K}_{\mathrm{Q}}=\frac{\mathrm{n}_{\mathrm{F}} \mathrm{Q}_{\mathrm{F}}+\mathrm{n}_{\mathrm{A}} \mathrm{Q}_{\mathrm{A}}}{\rho \mathrm{n}_{\mathrm{F}}^{3} \mathrm{D}_{\mathrm{F}}^{5}} \\
\eta_{\mathrm{O}}=\frac{\mathrm{J}}{2 \pi} \frac{\mathrm{K}_{\mathrm{T}}}{\mathrm{K}_{\mathrm{Q}}} ; \mathrm{J}=\frac{\mathrm{V}_{\mathrm{A}}}{\mathrm{n}_{\mathrm{F}} \mathrm{D}_{\mathrm{F}}}
\end{gathered}
$$

The reiteration is continued unless the thrust should be bigger than the required one and torque should be less than the previous stage.

\section{NUMERICAL APPROACH}

\section{Potential based boundary element method}

Suppose the forward propeller of a CRP with $\mathrm{Z}_{\mathrm{F}}$ blades rotates in the left hand (counter-clockwise) direction at a constant revolution number $\mathrm{n}_{\mathrm{F}}$, while the aft propeller $\mathrm{Z}_{\mathrm{A}}$ blades in the right hand (counter-clockwise) direction at $n_{A}$, and the CRP as a whole advances at a constant speed $\mathrm{V}_{\text {. }}$.

Assuming inviscid, incompressible and irrotational flow in the volume around and inside the body, a potential function exists for the perturbation velocity $\phi$ created by the propeller movement in the volume which satisfies the Laplace's equation. By applying Green's theorem for perturbation velocity potential $\phi$ at any field point on the body surface, we can get the following integral equation on the propeller and its trailing vortex wake.

$$
\begin{aligned}
2 \pi \phi(P)=\int_{S_{B}}\left\{\phi(q) \frac{\partial}{\partial n_{q}}\left(\frac{1}{R(p ; q)}\right)-\frac{\partial \phi(q)}{\partial n_{q}}\left(\frac{1}{R(p ; q)}\right)\right\} d S+ \\
+\int_{S_{W}} \Delta \phi(q) \frac{\partial}{\partial n_{q}}\left(\frac{1}{R(p ; q)}\right) d S
\end{aligned}
$$

$\mathrm{R}(\mathrm{p} ; \mathrm{q})$ is the distance from the field point $\mathrm{p}$ to the singularity point $\mathrm{q}$. This equation may be regarded as a representation of the velocity potential in terms of a normal dipole distribution of strength $\phi(p)$ on the body surface $S_{B}$, a source distribution of strength $\partial \phi / \partial \mathrm{n}$ on $\mathrm{S}_{\mathrm{B}}$, and a normal dipole distribution of strength $\Delta \phi(\mathrm{q})$ on the trailing wake surface $\mathrm{S}_{\mathrm{W}}$.

\section{Boundary conditions}

The strength of the source distribution in equation (6) is known from kinematic boundary condition (KBC) as follows:

$$
\frac{\partial \phi}{\partial \mathrm{n}}=-\overrightarrow{\mathrm{V}}_{\mathrm{I}} \cdot \overrightarrow{\mathrm{n}}=-\left[\mathrm{V}_{\mathrm{A}}+\vec{\omega} \times \overrightarrow{\mathrm{r}}\right] \cdot \overrightarrow{\mathrm{n}}
$$

where:

$\vec{n}-$ denotes the outward normal unit vector.

The strength of dipole distribution is unknown and equal to the perturbation potential on the propeller or to the potential jump in the trailing vortex wake. On the wake surface $S_{w}$, the velocity is considered to be continuous while the potential has a jump across the wake. It is expressed in the perturbation potential as:

$$
\Delta\left(\frac{\partial \phi}{\partial \mathrm{n}}\right)_{\mathrm{S}_{\mathrm{W}}}=\left(\frac{\partial \phi}{\partial \mathrm{n}}\right)^{\mathrm{B}}-\left(\frac{\partial \phi}{\partial \mathrm{n}}\right)^{\mathrm{F}}=0
$$




$$
(\Delta \phi)_{\mathrm{S}_{W}}=\phi^{\mathrm{B}}-\phi^{\mathrm{F}}=\Gamma
$$

where indexes $\mathrm{B}$ and $\mathrm{F}$ mean back and face sides of the propeller, respectively.

Another important physical boundary condition is the Kutta condition and its implementation. This equal pressure Kutta condition is applied to determine the unknown $\Delta \phi_{\mathrm{TE}}$ of the dipole strength on the wake surface. In the numerical calculation, the pressure Kutta condition at the back and face surfaces of the trailing edge (TE), can be expressed as:

$$
\Delta \mathrm{p}_{\mathrm{TE}}=\mathrm{p}_{\mathrm{TE}}^{\mathrm{B}}-\mathrm{p}_{\mathrm{TE}}^{\mathrm{F}}=0
$$

A direct solution of the resulting system of equations obtained from discretized Green's formula for the perturbation velocity potential (6), along with equation (10) is difficult due to the nonlinear character of the equation (6) therefore, an iterative solutions algorithm is employed to solve the problem. We focus on the numerical implementation in the following section.

Discretization of equation (6) leads to a linear system of algebraic equations for the unknown $\phi$ as:

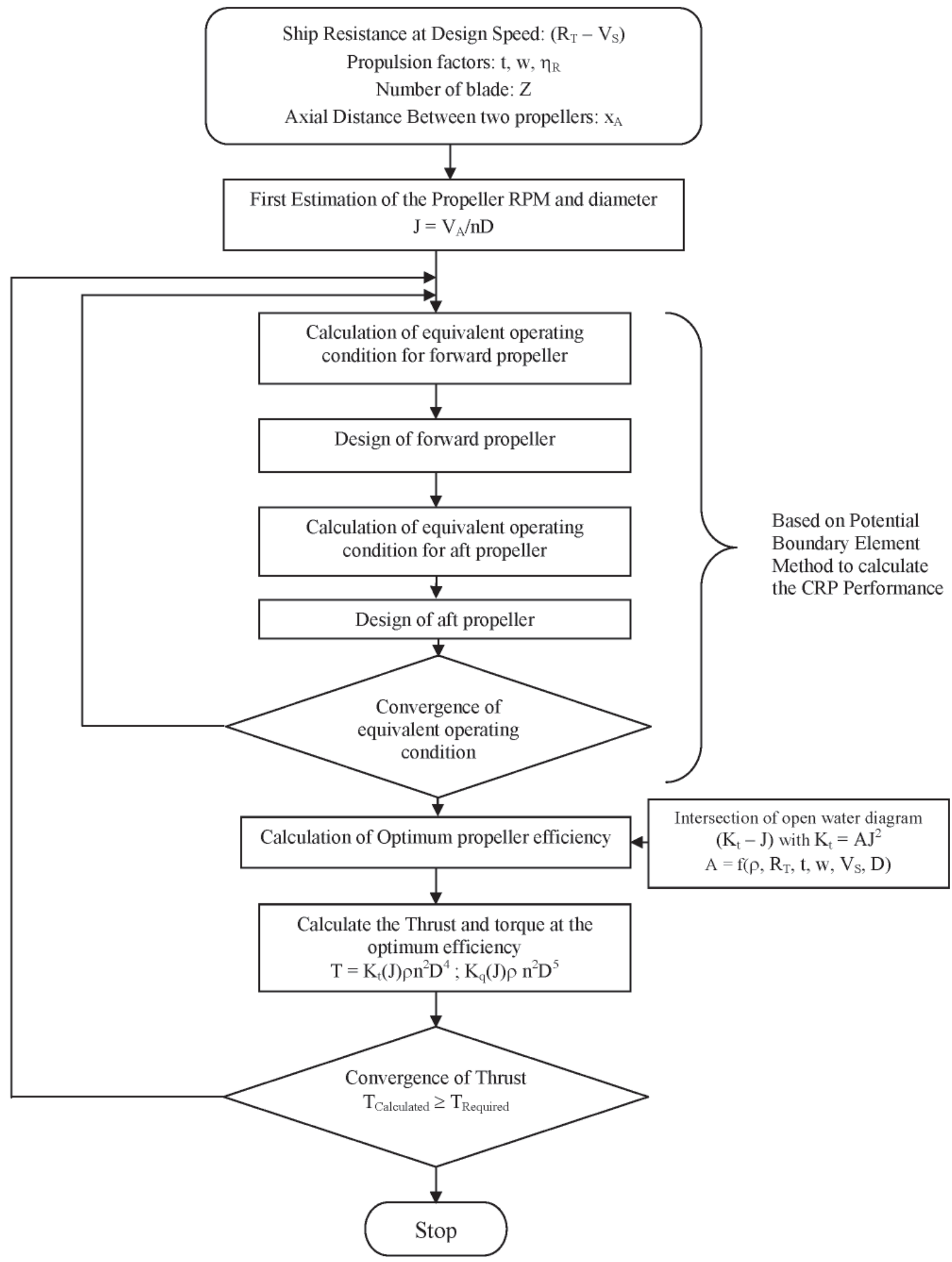

Fig. 1. Calculation flowchart of CRP 


$$
\begin{aligned}
& 2 \pi \phi_{\mathrm{i}}=\sum_{\mathrm{N}_{\mathrm{p}}=1}^{2}\left(\sum_{\mathrm{k}=1}^{\mathrm{K}} \sum_{\mathrm{j}=1}^{\mathrm{N}_{\text {tot }}} \mathrm{D}_{\mathrm{ij}}^{\mathrm{k}}\left(\phi_{\mathrm{j}}\right)\right)+ \\
& +\sum_{N_{p}=1}^{2}\left(\sum_{k=1}^{K} \sum_{j=1}^{M} \sum_{i=1}^{N_{W}} W_{i j l}^{k}\left(\Delta \phi_{j}\right)\right)+ \\
& +\sum_{\mathrm{N}_{\mathrm{p}}=1}^{2}\left(\sum_{\mathrm{k}=1}^{\mathrm{K}} \sum_{\mathrm{j}=1}^{\mathrm{N}_{\mathrm{tot}}} \mathrm{S}_{\mathrm{ij}}^{\mathrm{k}}\left(\frac{\partial \phi}{\partial \mathrm{n}}\right)_{\mathrm{j}}\right) \\
& \mathrm{i}=1,2, \ldots, \mathrm{N}_{\text {tot }} \text {; where: } \mathrm{N}_{\text {tot }}=2 \times \mathrm{N} \times \mathrm{M} \\
& \mathrm{K} \text { - number of blades }
\end{aligned}
$$

Where $\mathrm{D}_{\mathrm{ij}}^{\mathrm{k}}, \mathrm{W}_{\mathrm{ijl}}^{\mathrm{k}}$ (dipole distributions on body and wake surfaces) and $S_{i j}^{\mathrm{k}}$ (source: distribution on body) are influence coefficients on panel $\mathrm{j}$ acting on the control point of panel $\mathrm{i}$. Those influence coefficients are nearly evaluated analytically. The use of quadrilateral surface panels instead of planar panels has been found to be important for the convergence of the present potential based boundary element method. It is found to be especially so when applied to the highly skewed propeller and twisted shape.

\section{Calculation of induced velocity}

From Green's theorem in the potential field, equation (6), we can alternatively construct in the velocity field. Taking the gradient of the perturbation velocity potential at any field point, the induced velocity which can be expressed as:

$$
\begin{gathered}
4 \pi \overrightarrow{\mathrm{v}}(\mathrm{p})=\int_{\mathrm{S}_{\mathrm{B}}}\left\{\phi(\mathrm{q}) \nabla_{\mathrm{p}} \frac{\partial}{\partial \mathrm{n}_{\mathrm{q}}}\left(\frac{1}{\mathrm{R}(\mathrm{p} ; \mathrm{q})}\right)+\right. \\
\left.-\frac{\partial \phi(\mathrm{q})}{\partial \mathrm{n}_{\mathrm{q}}} \nabla_{\mathrm{p}}\left(\frac{1}{\mathrm{R}(\mathrm{p} ; \mathrm{q})}\right)\right\} \mathrm{d} \mathrm{S}+ \\
+\int_{\mathrm{S}_{W}} \Delta \phi \nabla_{\mathrm{p}} \frac{\partial}{\partial \mathrm{n}_{\mathrm{q}}}\left(\frac{1}{\mathrm{R}(\mathrm{p} ; \mathrm{q})}\right) \mathrm{dS}
\end{gathered}
$$

Here, from the discretization of the body and wake, and assuming the potential $\varphi$ and the value of $\partial \varphi / \partial$ n are constant within each panel. Then, equation (12) can be written by:

$$
\begin{aligned}
& 4 \pi \overrightarrow{\mathrm{V}}_{\mathrm{i}}=\sum_{\mathrm{N}_{\mathrm{p}}=1}^{2}\left(\sum_{\mathrm{k}=1}^{\mathrm{K}} \sum_{\mathrm{j}=1}^{\mathrm{N}_{\text {tot }}}\left(\phi_{\mathrm{j}}\right) \nabla_{\mathrm{p}} \mathrm{C}_{\mathrm{ij}}^{\mathrm{k}}\right)+ \\
& +\sum_{\mathrm{N}_{\mathrm{p}}=1}^{2}\left(\sum_{\mathrm{k}=1}^{\mathrm{K}} \sum_{\mathrm{j}=1}^{\mathrm{M}}\left(\Delta \phi_{\mathrm{j}}\right) \nabla_{\mathrm{p}} \mathrm{W}_{\mathrm{ij} \mathrm{l}}^{\mathrm{k}}\right)+ \\
& +\sum_{\mathrm{N}_{\mathrm{p}}=1}^{2}\left(\sum_{\mathrm{k}=1}^{\mathrm{K}} \sum_{\mathrm{j}=1}^{\mathrm{N}_{\text {tot }}}\left(\frac{\partial \phi}{\partial \mathrm{n}}\right)_{\mathrm{j}}^{\mathrm{k}} \nabla_{\mathrm{p}} \mathrm{S}_{\mathrm{ij}}^{\mathrm{k}}\right)
\end{aligned}
$$

Where $\nabla_{\mathrm{p}} \mathrm{C}_{\mathrm{ii}}^{\mathrm{k}}, \nabla_{\mathrm{p}} \mathrm{W}_{\mathrm{ijl}}^{\mathrm{k}}$ and $\nabla_{\mathrm{p}} \mathrm{S}_{\mathrm{ii}}^{\mathrm{k}}$ are the velocity influence coefficients. Those velocity coefficients can be evaluated analytically by assuming that the surface elements are approximated by a number of quadrilateral hyperboloidal panels.

Calculations of the velocity influence were more sensitive than the potential coefficient, and also the required storage was three times more than the storage of the potential coefficient. There was one big advantage that the velocities can directly be obtained for any field points

The induced velocity diagram of the CRP is shown in Fig. 2, where $u_{a}$ and $u_{t}$ denotes the axial and circumferential induced velocities, respectively. Since the interaction between two propellers, the total induced velocities may be expressed as follows:

$$
\begin{aligned}
& \left(\mathrm{u}_{\mathrm{a}}\right)_{\mathrm{i}}=\left(\mathrm{u}_{\mathrm{a}}\right)_{\mathrm{ii}}+\left(\mathrm{u}_{\mathrm{a}}\right)_{\mathrm{ij}} \\
& \left(\mathrm{u}_{\mathrm{t}}\right)_{\mathrm{i}}=\left(\mathrm{u}_{\mathrm{t}}\right)_{\mathrm{ii}}+\left(\mathrm{u}_{\mathrm{t}}\right)_{\mathrm{ij}}
\end{aligned}
$$

For two fore and aft propellers, it is given:

$$
\begin{gathered}
\left(\mathrm{u}_{\mathrm{a}}\right)_{1}=\left(\mathrm{u}_{\mathrm{a}}\right)_{11} ;\left(\mathrm{u}_{\mathrm{a}}\right)_{2}=\left(\mathrm{u}_{\mathrm{a}}\right)_{22}+\left(\mathrm{u}_{\mathrm{a}}\right)_{21} \\
\left(\mathrm{u}_{\mathrm{t}}\right)_{1}=\left(\mathrm{u}_{\mathrm{t}}\right)_{11} ;\left(\mathrm{u}_{\mathrm{t}}\right)_{2}=\left(\mathrm{u}_{\mathrm{t}}\right)_{22}+\left(\mathrm{u}_{\mathrm{t}}\right)_{21}
\end{gathered}
$$

Where $\left(\mathrm{u}_{\mathrm{a}(\mathrm{t})}\right)_{\mathrm{ij}}$ implies the axial or circumferential velocities at $i$-th propeller induced by the $j$-th propeller. The subscript 1 and 2 denote the forward or aft propeller, respectively. We observe that $\left(\mathrm{u}_{\mathrm{a}}\right)_{21}$ is zero and $\left(\mathrm{u}_{\mathrm{t}}\right)_{21}$ is very small and neglected.

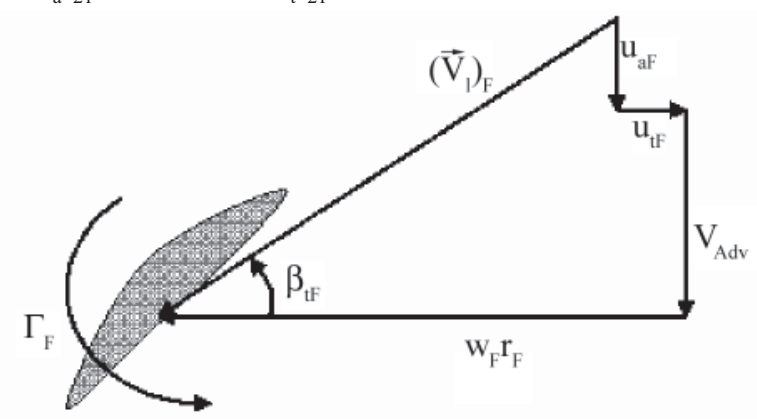

Foreward propeller

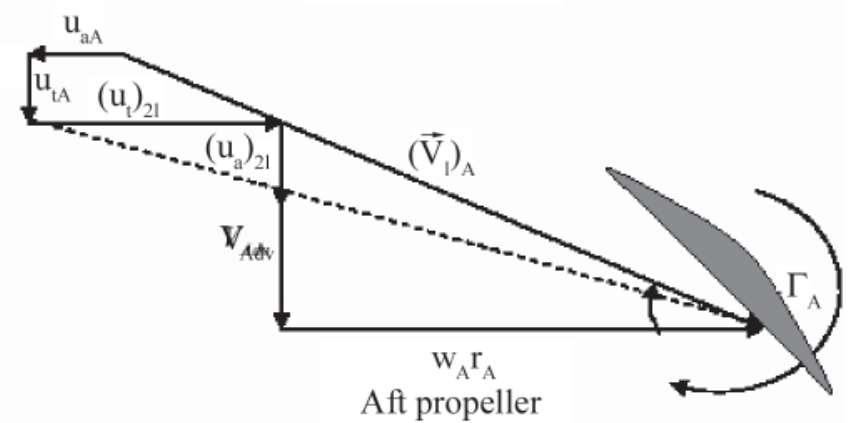

Fig. 2. Relative Velocities at Blade section of CRP

The hydrodynamic pitch angle and resultant velocities to the fore and aft propellers are expressed as follows:

$$
\begin{aligned}
& \tan \beta_{\mathrm{iF}}=\frac{\mathrm{V}_{\mathrm{Adv}}+\mathrm{u}_{\mathrm{aF}}}{\omega_{\mathrm{F}} \mathrm{r}_{\mathrm{F}}+\mathrm{u}_{\mathrm{tF}}} \\
& \tan \beta_{\mathrm{iA}_{\mathrm{A}}}=\frac{\mathrm{V}_{\mathrm{Adv}}+\mathrm{u}_{\mathrm{aA}}+\left(\mathrm{u}_{\mathrm{a}}\right)_{21}}{\omega_{\mathrm{F}} \mathrm{r}_{\mathrm{F}}-\mathrm{u}_{\mathrm{tA}}+\left(\mathrm{u}_{\mathrm{t}}\right)_{21}}
\end{aligned}
$$

Inflow velocity to the fore propeller may be obtained by:

$$
\begin{aligned}
& \overrightarrow{\mathrm{V}}_{\mathrm{IF}}=\overrightarrow{\mathrm{V}}_{\mathrm{Adv}}+\overrightarrow{\mathrm{u}}_{\mathrm{aF}}+\vec{\omega}_{\mathrm{F}} \times \overrightarrow{\mathrm{r}}_{\mathrm{F}}-\overrightarrow{\mathrm{u}}_{\mathrm{tF}} \\
& \mathrm{V}_{\mathrm{IF}}=\sqrt{\left(\mathrm{V}_{\mathrm{Adv}}+\mathrm{u}_{\mathrm{aF}}\right)^{2}+\left(2 \pi \mathrm{r}_{\mathrm{F}} \mathrm{n}_{\mathrm{F}}-\mathrm{u}_{\mathrm{tF}}\right)^{2}}
\end{aligned}
$$


Inflow velocity to the aft propeller is expressed by:

$\overrightarrow{\mathrm{V}}_{\mathrm{IA}}=\overrightarrow{\mathrm{V}}_{\mathrm{Adv}}+\overrightarrow{\mathrm{u}}_{\mathrm{aA}}+\left(\overrightarrow{\mathrm{u}}_{\mathrm{a}}\right)_{21}+\vec{\omega}_{\mathrm{A}} \times \overrightarrow{\mathrm{r}}_{\mathrm{AF}}-\overrightarrow{\mathrm{u}}_{\mathrm{tA}}+\left(\overrightarrow{\mathrm{u}}_{\mathrm{t}}\right)_{21}$

$\mathrm{V}_{\mathrm{IA}}=\sqrt{\left(\mathrm{V}_{\mathrm{Adv}}+\mathrm{u}_{\mathrm{aA}}+\left(\mathrm{u}_{\mathrm{a}}\right)_{21}\right)^{2}+\left(2 \pi \mathrm{r}_{\mathrm{A}} \mathrm{n}_{\mathrm{A}}-\mathrm{u}_{\mathrm{tA}_{\mathrm{A}}}+\left(\mathrm{u}_{\mathrm{t}}\right)_{21}\right)^{2}}$

\section{NUMERICAL RESULTS AND DISCUSSION}

\section{Application of the CRP system on the bulk carrier and VLCC}

We applied the method on two CRP for two different ship types where the model tests have been done in IHI and were available [9] and [10]. Main dimensions for bulk carrier and VLCC are given in Tab. 1.

Tab. 1. Main dimensions of the Bulk Carrier and VLCC

\begin{tabular}{|c|c|c|}
\hline Ship Type & $\begin{array}{c}\text { Bulk Carrier } \\
\text { (Juno) }\end{array}$ & VLCC \\
\hline Length (LBP)[m] & 178.0 & 314.0 \\
\hline Breadth [m] & 28.4 & 58.0 \\
\hline Depth [m] & 10.72 & 19.5 \\
\hline Dead Weight & 37000 & - \\
\hline Speed at full load [Knot] & 15 & 16 \\
\hline
\end{tabular}

For each vessel, conventional propeller and CRP have been used and the results are compared. The CRP5022 and conventional propeller (single propeller MP588) for the bulk carrier and CRP5029 and MP620 for VLCC have been selected. The principal of particulars of the both CRP propeller and single propeller are given in Tab. 2 and Tab. 3.

Tab. 2. Principal particulars of CRP and single propellers for Bulk Carrier

\begin{tabular}{|c|c|c|c|}
\hline \multirow{2}{*}{$\begin{array}{r}\text { Propeller. } \\
\text { Type }\end{array}$} & $\begin{array}{c}\text { Single } \\
\text { Propeller } \\
\text { MP588 }\end{array}$ & \multicolumn{2}{|c|}{$\begin{array}{c}\text { Contra-Rotating } \\
\text { Propeller CRP5022 }\end{array}$} \\
\cline { 3 - 4 } & Foreward & Aft \\
\hline D [mm] for model tset & 277.6 & 250.0 & 213.9 \\
\hline D [m] for ship & 5.23 & 4.71 & 4.03 \\
\hline Boss Ratio & 0.20 & 0.20 & 0.18 \\
\hline Z & 4 & 4 & 5 \\
\hline P/D & 0.6 & 0.70 & 0.80 \\
\hline EAR & 0.62 & 0.42 & 0.45 \\
\hline Skew angle [deg.] & 7 & 20 & 20 \\
\hline Direction of Rotation & Left hand & Left hand & $\begin{array}{c}\text { Right } \\
\text { Hand }\end{array}$ \\
\hline Section & MAU & MAU & MAU \\
\hline
\end{tabular}

Tab. 3. Principal particulars of CRP and single propellers for VLCC

\begin{tabular}{|c|c|c|c|}
\hline \multirow{2}{*}{$\begin{array}{r}\text { Propeller. } \\
\text { Type }\end{array}$} & \multirow{2}{*}{$\begin{array}{c}\text { Single } \\
\text { Propeller } \\
\text { MP620 }\end{array}$} & \multicolumn{2}{c|}{$\begin{array}{c}\text { Contra-Rotating } \\
\text { Propeller CRP5029 }\end{array}$} \\
\cline { 3 - 4 } & Foreward & Aft \\
\hline D [mm] (model) & 269.3 & 250.0 & 221.0 \\
\hline D [m] (VLCC) & 10.20 & 9.47 & 8.37 \\
\hline Boss Ratio & 0.15 & 0.20 & 0.18 \\
\hline Z & 5 & 4 & 5 \\
\hline P/D & 0.79 & 0.92 & 0.93 \\
\hline EAR & 0.55 & 0.35 & 0.35 \\
\hline Skew angle [Deg.] & 20 & 20 & 18 \\
\hline Direction of Rotation & Left hand & Left hand & $\begin{array}{c}\text { Right } \\
\text { hand }\end{array}$ \\
\hline Section & MAU & MAU & MAU \\
\hline
\end{tabular}

\section{Grid generation}

As known that the BEM is dealing with boundary of the body, so the grid generation is the necessary starting point for

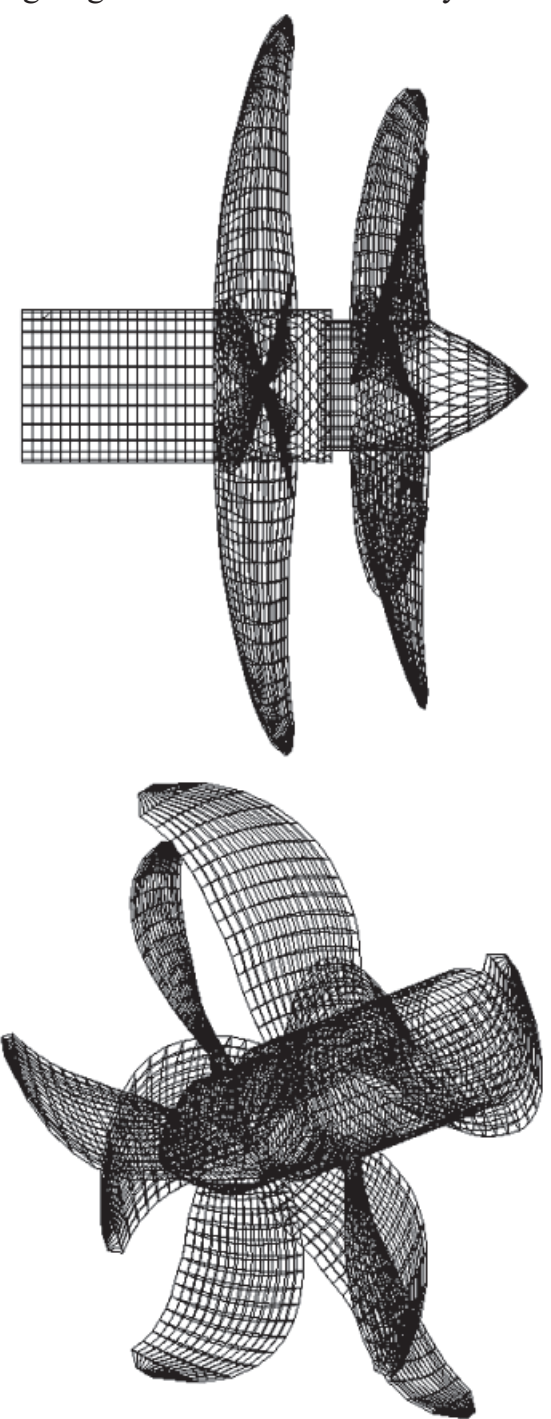

Fig. 3. Surface Mesh on CRP5022 


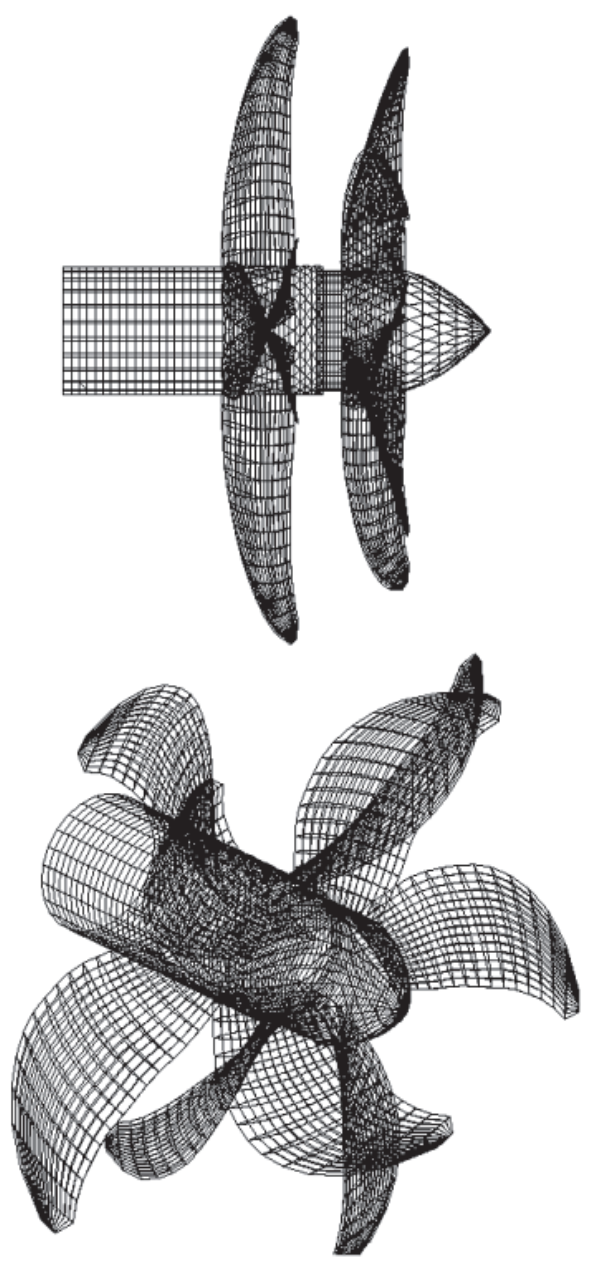

Fig. 4. Surface Mesh on CRP 5029

numerical implementation. The coordinate of the discretized surface should be sufficiently accurate since any inaccuracy can lead the hydrodynamic pressure to become noisy. According to our experience, the hyperboloidal quadrilateral element seems to be better than other elements like triangular and super element. Higher order element (quadratic or cubic order) is very complicated way to apply although it gives more precise results. This is our future plan to be done. However, for the present calculation and prepared SPD code, the hyperboloidal quadrilateral elements are used to discretize the whole body (hub and two propellers).

\section{HYDRODYNAMICS CHARACTERISTICS AND DETERMINATION OF DESIGN POINT}

Numerical results of the open water characteristics are compared with the experimental data for the CRP and conventional propellers. It is shown that the numerical results of the present method are very accurate and in good agreement with the experimental data for the open-water characteristics.

Using the equations ( 1 ) and (2), $\left(\mathrm{K}_{\mathrm{T}}=\mathrm{A} \cdot \mathrm{J}^{2} ; \mathrm{K}_{\mathrm{T}}=\mathrm{B} \cdot \mathrm{J}^{2}\right)$, in the figures of 5 and 6 , intersection points are obtained between the thrust coefficients for each conventional and CRP propellers. Tab. 4 is shown the efficiency of each propeller (conventional and CRP) obtained from the figures 5 and 6 at the intersection points of Kt.

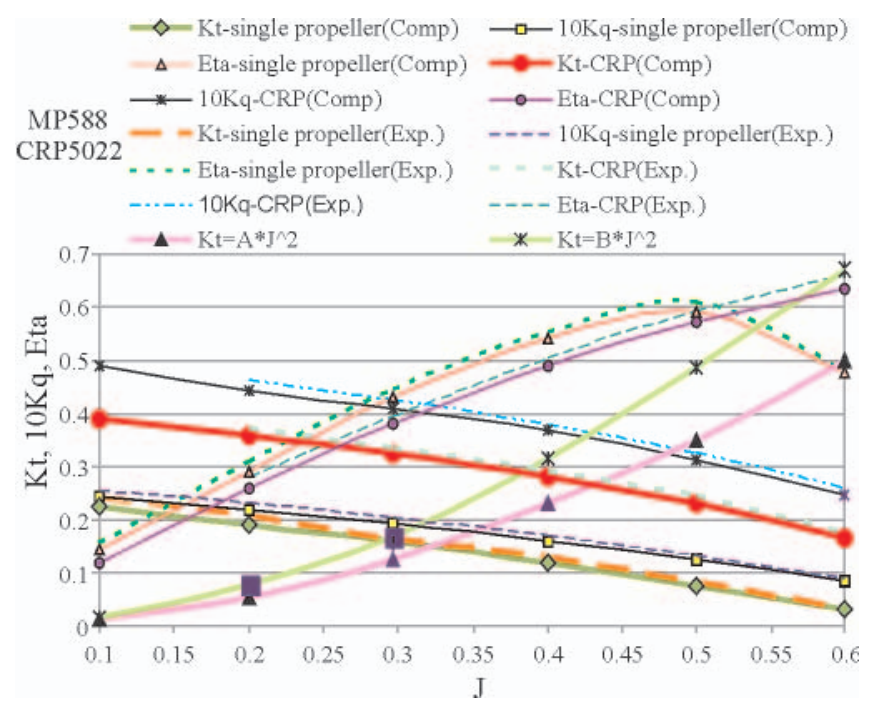

Fig. 5. Comparison of open water characteristics of conventional and CRP propellers for the Bulk-Carrier and the determination of Design point

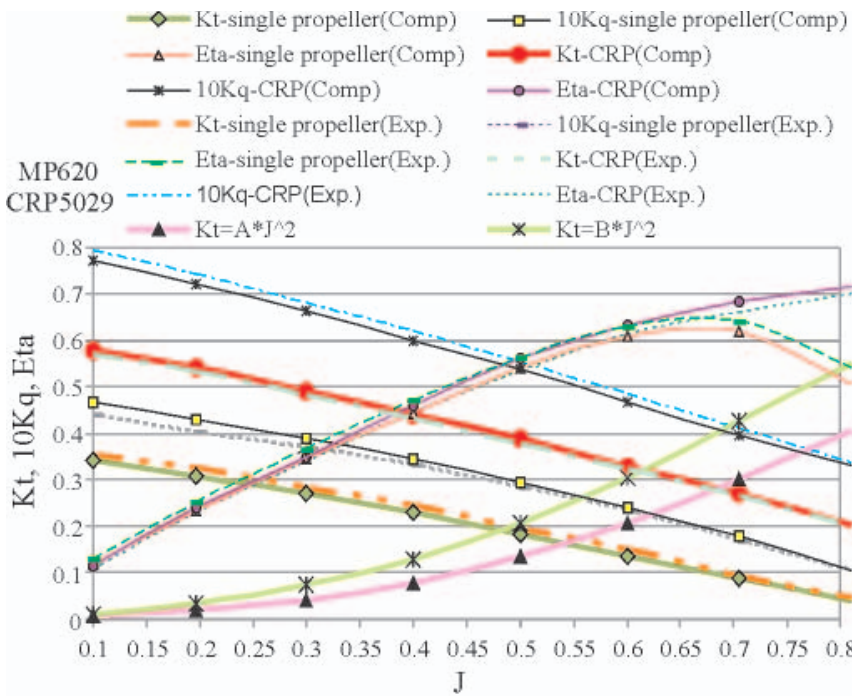

Fig. 6. Comparison of open water characteristics of conventional and CRP propellers for the VLCC and the determination of Design point

Tab. 4. Comparison of Experimental and Calculated Efficiency for Types of Ships

\begin{tabular}{|c|c|c|c|c|}
\hline Ship Type & \multicolumn{2}{|c|}{ VLCC } & \multicolumn{2}{c|}{ Bulk-Carrier } \\
\hline $\begin{array}{c}\text { Propeller } \\
\text { Type }\end{array}$ & MP620 & CRP5029 & MP588 & CRP5022 \\
\hline $\begin{array}{c}\text { Intersection } \\
\text { point of Kt }\end{array}$ & $\begin{array}{l}\mathrm{J}_{\text {Exp. }}=0.54 \\
J_{\text {Cal. }}=0.55\end{array}$ & $\begin{array}{l}\mathrm{J}_{\text {Exp. }}=0.62 \\
\mathrm{Cal}_{\text {Cal. }}=0.61\end{array}$ & $\begin{array}{l}\mathrm{J}_{\text {Exp. }}=0.32 \\
\mathrm{~J}_{\text {Cal. }}=0.325\end{array}$ & $\begin{array}{l}\mathrm{J}_{\text {Exp. }}=0.375 \\
\mathrm{~J}_{\text {Cal. }}=0.38\end{array}$ \\
\hline$\eta_{\mathrm{o}}($ Exp.) & 0.59 & 0.63 & 0.479 & 0.490 \\
\hline$\eta_{\mathrm{o}}($ cal.) & 0.57 & 0.64 & 0.467 & 0.469 \\
\hline
\end{tabular}

\section{CONCLUSIONS}

In this paper, we numerically calculated the open water characteristics of the conventional and CCRP and obtained 
the optimum operational condition for the large vessel using BEM. According to the results, following conclusions are drawn:

The present method can be applied to any complicated propeller configuration and determine the open water characteristics.

The CCRP system may raise the propeller efficiency around 2-3 percent at design condition for the present system.

Design point is determined based on highest efficiency which is matched the generated propeller thrust and ship required thrust.

\section{BIBLIOGRAPHY}

1. Yang, C-J, Tamashima, M., Wang, G., Tamazaki R. and Kuizuka, H.: Prediction of the steady performance of Contrarotating Propeller by Lifting Surface Theory, Transaction of the West-Japan Society of Naval Architects, Vol. 83, 1992

2. Nakamura, S., Ohta, T., Yonekura, K., Sasajima, T. and Saki, K.: World's First Contra-rotating Propeller System Successful Fitted to a Merchant Ship, The Motor Ship, Proceedings of $11^{\text {th }}$ International Marine Propulsion Conf. 9-10 March 1989

3. Rutundi, C.F.: Trials of the Training Ship Cristoforo Colombo with two Screws on a Common Axis, Trans. Institution of Naval Architects, 1934

4. Lee, C-S, Kim, Y.G, Baek, M-C., Yoo, J-H.: Numerical Prediction of Steady and Steardy Performance of Contrarotating Propellers, Journal of Hydrospace Technology, Vol. 1 No. 1, 1995, pp. 29-40

5. Chen, B.Y-H, Tseng, C. L.: A Contra-rotating Propellers Design for a High Speed Patrol Boat with Pod Propulsion, FAST'95

6. Ukon, Y., Ohashi, K., Fujisawa, J., Hasegawa, J.: Propulsive Performance of a Contra-rotating Podded Propulsor, T-Pod Conference, Newcastle, April 2004
7. Chenjun, Y., Guiqiang, W.: Hydrodynamic Performance of Contra-rotating Propellers (CRP), Numerical Analysis, China Society of Naval Architecture and Marine Engineering, Vol. 7, 1992

8. Islam, M.F., Veitch, B., Bose N., Liu P. : Numerical Study of Hub Taper Angle Podded propeller Performance, J. of Marine Technology, Vol. 43, No. 1, January 2006, pp.1-10

9. Nishiyama, S., Sakamoto, Y., Fujino, R.,: Contra-rotating Propeller System for Large Merchant Ships, Technical Bulletin of IHI, 1991

10.Nishiyama, S., Sakamoto, Y., Ishida, S, Fujino, R. and Oshima, M.,: Development of Contra-rotating Propeller for Juno - A 37,000 DWT Class Bulk Carrier, Trans. SNAME, Vol. 98, 1990

11.Bjarrne, E.: Systematic Studies of contra-rotating Propellers for Merchant Ship, Proc. IMAS'73, 1973, pp.49-59

12.Ghassemi, H., Allievi, A., : "A Computational Method for the Analysis of Fluid Flow and Hydrodynamic Performance of Conventional and Podded Propulsion Systems", Journal of Oceanic Engineering International, Vol. 3, No. 2, 1999

13.Koronowicz T., Tuszkowska T., Waberska G.: Computer software system for determining the pressure field resulting from hull flow and operation of the marine propeller. Polish Maritime Research, December 1997

14.Ukon, Y. et. al.:" On the Design of Contra-rotating Propellers - Application to High Speed Container Ship", Trans. Of the West -Japan Society of Naval Architects, Vol. 25, 1988, pp.52-64.

\section{CONTACT WITH THE AUTHOR}

Hassan Ghassemi, Assoc. Prof.

Faculty of Marine Technology

Amirkabir University of Technology

Hafez Ave.,

Tehran, IRAN

e-mail: gasemi@cic.aut.ac.ir

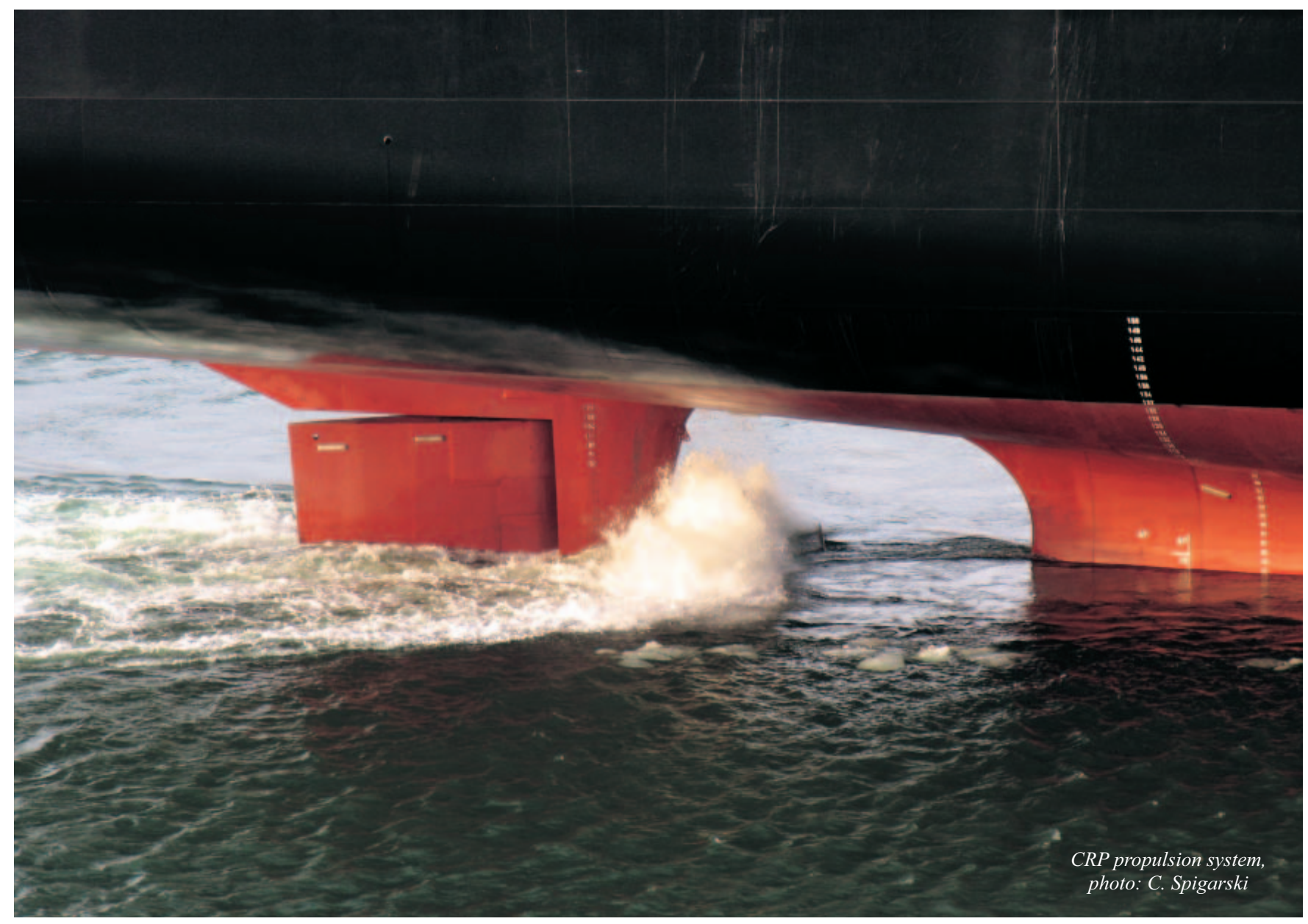

